\title{
Molluscum-like lesions in cryptococcal meningitis
}

\author{
Alka Sharma $\cdot$ Sourabh Aggarwal $\cdot$ \\ Vishal Sharma
}

Received: 25 April 2010/Accepted: 12 May 2010/Published online: 11 June 2010

(C) SIMI 2010

A 45-year-old man presented with fever and headache for 15 days. He had been reported to have an altered sensorium for 6 days prior to presentation. He did not have a known case of HIV/AIDS. There was no history of blood transfusions in the past. On physical examination, the patient had nuchal rigidity. The patient also had skin lesions on his eyelids (Fig. 1). The cerebrospinal fluid (CSF) examination revealed 10 cells, all lymphocytes, glucose level $28 \mathrm{mg} / \mathrm{dL}$ (normal $40-70 \mathrm{mg} / \mathrm{dL}$ ) and a protein level of $88 \mathrm{mg} / \mathrm{dL}$ (normal 15-50 mg/dL). He was found to be positive for the AIDS virus (HIV1).

An India ink preparation of the CSF revealed capsulated yeast cells, and culture confirmed the etiology as Cryptococcus neoformans. The patient was started on amphotericin B, but he died 2 days post presentation.

Although the lesions seen in Fig. 1 are usually characteristic of a viral infection by Molluscum contagiosum, this would not explain the clinical features of meningitis. These viral lesions are common in HIV patients; however, Molluscum contagiosum does not usually result in meningitis, and therefore is unlikely to be the cause in this case. Infection with Penicillium marneffei can also present with cutaneous lesions resembling Molluscum, but meningitis is rare [1].

Papular lesions with central umbilication resembling molluscum contagiosum are a rare manifestation of cryptococcal infection [2]. Such lesions can also be found

A. Sharma $\cdot$ S. Aggarwal · V. Sharma

Department of Medicine, University College of Medical

Sciences and GTBH, Delhi, India

S. Aggarwal $(\bowtie)$

257/6, Central Town, Jalandhar City 144001, India

e-mail: drsourabh79@gmail.com typically on the face, scalp and upper trunk. Cryptococcus is one of the leading infectious causes of meningitis, and can be accompanied by Molluscum-like lesions. The cutaneous biopsy confirmed the presence of cryptococcal organisms. These lesions are a late manifestation of cryptococcal infection. Early diagnosis can occur only if the diagnosis is considered, and therefore the clinician needs to consider cryptococcal infection as a possible cause of chronic and subacute meningitis. Most patients will lack any specific clue to cryptococcal infection [3]. The cases may be diagnosed early by making it a policy to do India ink staining and cryptococcal antigen testing on all CSF specimens. Complications of the meningitis may include elevated intracranial pressure, visual impairment and cerebral infarction [4]. This is important because cryptococcal meningitis can lead to a mortality of around 10-30\% in HIV-related cases. Cryptococcal meningitis is treated with intravenous amphotericin $\mathrm{B}$, at a dose of $0.7 \mathrm{mg} / \mathrm{kg}$ daily, with flucytosine, $25 \mathrm{mg} / \mathrm{kg}$ qid for the

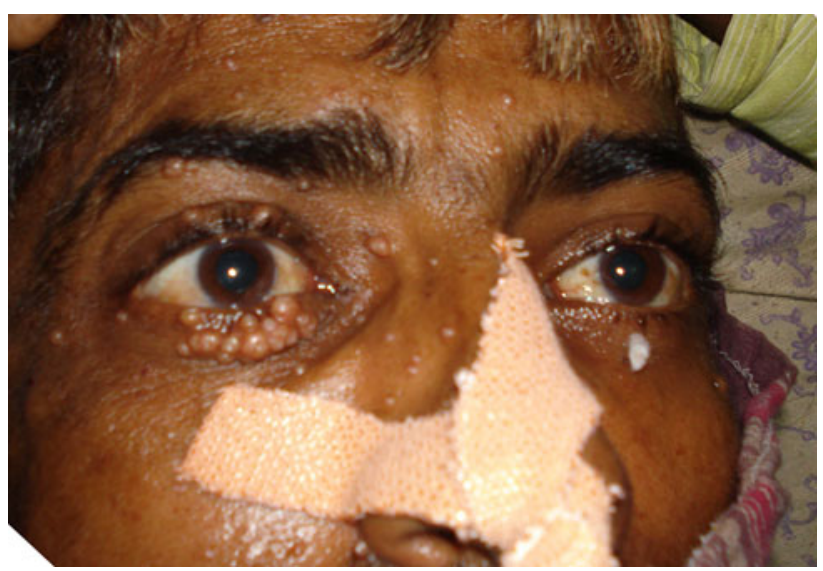

Fig. 1 Molluscum like lesions on right eyelid 
initial 2 weeks. Following this the treatment is continued with fluconazole daily, $400 \mathrm{mg}$ PO for 10 weeks. Fluconazole has to be continued at a dose of $200 \mathrm{mg} /$ day until the CD4+ T-cell count remained above 200 cells/L for at least 6 months in response to HAART.

\section{Conflict of interest None.}

\section{References}

1. Supparatpinyo K, Khamwan C, Baosoung V, Nelson KE, Sirisanthana T (1994) Disseminated Penicillium marneffei infection in southeast Asia. Lancet 344:110-113
2. de Souza JA (2006) Molluscum or a mimic? Am J Med 119:927929

3. Bicanic T, Harrison TS (2005) Cryptococcal meningitis. Br Med Bull 72:99-118

4. Day JN (2004) Cryptococcal meningitis. Pract Neurol 4:274-285 